\title{
Antioxidant activity, total flavonoid, and total tannin content of ethanol extract of avocado peel (Persea americana Mill.)
}

\section{Aktivitas antioksidan, kandungan flavonoid total, dan tanin total ekstrak etanol kulit buah alpukat (Persea americana Mill.)}

\author{
Rini Isromarina1*, Doddy Rusli¹, Deva Ulan Sari ${ }^{1}$ \\ ${ }^{1}$ Bhakti Pertiwi College of Pharmacy, Palembang, Indonesia \\ *Corresponding author: riniisromarina@gmail.com
}

\begin{abstract}
Background: Avocado is a plant that can grow in tropical climates. In general, people only consume the fruit while the skin and seeds are not used. Avocado fruit, skin and seeds contain secondary metabolites such as flavonoids and tannins which have antioxidant activity.

Objective: To determine antioxidant activity, total flavonoid, and total tannin content of the ethanol extract of avocado peel.

Methods: P. americana Mill. was collected from Lubuk Linggau, South Sumatra. The ethanol extract of $P$. americana Mill. peel obtained by maceration with ethanol. Qualitative analysis of flavonoids using Mg and $\mathrm{HCl}$ while tannins using $\mathrm{FeCl}_{3}$. Determination of total flavonoid content was carried out with $\mathrm{AlCl}_{3}$ reagent and Folin-Ciocalteu reagent to determine the total tannin content and was measured by a UV-Vis Spectrophotometer. Determination of antioxidant activity using the DPPH method.

Result: The results of the qualitative analysis showed that ethanol extract of avocado peel contained flavonoids and tannins. It also had antioxidant activity with IC 50 of $41,93 \mu \mathrm{g} / \mathrm{mL}$. The total flavonoid and tannin content of it were 125,01 mgQE/g extract and 53,82 mgTAE/g extract respectively.

Conclusion: Ethanol extract of avocado peel had antioxidant activity, while the total flavonoid compounds was higher than the total tannins.
\end{abstract}

Keywords: antioxidant, DPPH, total flavonoid, total tannins

\section{Intisari}

Latar Belakang: Buah, kulit dan biji alpukat mengandung metabolit sekunder seperti flavonoid dan tanin yang memiliki aktivitas antioksidan. Namun, penelitian terkait kulit alpukat sebagai antioksidan belum banyak dilakukan.

Tujuan: Mengetahui aktivitas antioksidan total flavonoid, total tanin ekstrak etanol kulit alpukat.

Metode: Buah alpukat yang diperoleh dari Lubuk Linggau, Sumatra Selatan diekstraksi dengan cara maserasi dengan pelarut etanol. Ekstrak kemudian dianalisis kualitatif untuk mengetahui kandungan flavonoid menggunakan $\mathrm{Mg}$ dan $\mathrm{HCl}$ dan tanin menggunakan $\mathrm{FeCl}_{3}$. Penentuan aktivitas antioksidan ekstrak dilakukan dengan metode DPPH, sedangkan penentuan flavonoid total menggunakan $\mathrm{AICI}_{3}$ serta tanin total menggunakan reagen folin ciocelteu yang diukur menggunakan spektrofotometer UV-VIS.

Hasil: Hasil analisis kualitatif memperlihatkan bahwa ekstrak etanol kulit alpukat mengandung flavonoid dan tanin. Esktrak etanol kulit alpukat memiliki aktivitas antioksidan kuat dengan $\mathrm{IC}_{50} 41,93 \mu \mathrm{g} / \mathrm{mL}$. Kandungan flavonoid total dan tanin total ekstrak etanol kulit alpukat masing-masing adalah 125,01 mgQE/g ekstrak dan 53,82 mgTAE/g ekstrak.

Kesimpulan: Ekstrak etanol kulit alpukat memiliki aktivitas antioksidan dengan kandungan flavonoid yang lebih tinggi dibandingkan tanin.

Katakunci: antioksidan, DPPH, flavonoid total, tanin total

\section{Pendahuluan}

Persea americana Mill. merupakan tanaman yang memiliki khasiat sebagai obat, salah satunya sebagai penangkal radikal bebas. Tanaman ini banyak tumbuh pada daerah tropis seperti 
Sumatera Selatan. Pada umumnya masyarakat hanya mengkonsumi buahnya saja, sedangkan kulit dan bijinya tidak dimanfaatkan padahal mengandung senyawa metabolit sekunder yang berkhasiat obat, salah satunya adalah sebagai antioksidan. Antioksidan merupakan senyawa pendonor elektron dengan cara memberikan satu elektronnya kepada senyawa yang bersifat radikal sehingga senyawa radikal tersebut menjadi stabil. Kestabilan terjadi karena elektron pada kulit terluar senyawa radikal menjadi lengkap dan reaksi berantai menjadi terhambat (Winarsi, 2007). Radikal bebas harus distabilkan karena dapat merusak sel sehat sehingga kehilangan fungsi dan struktur sel sehat apabila masuk ke dalam tubuh. Kerusakan sel yang terjadi dapat mengakibatkan beberapa penyakit dan penuaan dini (Liochev, 2013). Kulit, buah dan biji $P$. americana Mill. mengandung senyawa fenol, flavonoid dan tanin (Aminah dkk, 2017; Vinha 2013; Malangngi 2012). Flavonoid dan tanin merupakan golongan senyawa fenol yang memiliki gugus $\mathrm{OH}$ yang dapat meredam radikal bebas. Berdasarkan hal tersebut maka dilakukan penelitian tentang aktivitas antioksidan, total flavonoid, dan tanin kulit buah alpukat yang tumbuh di daerah Lubuk Linggau, Sumatera Selatan.

\section{Metode}

\subsection{Alat dan bahan}

Alat yang digunakan adalah botol gelap, alat gelas (pyrex), timbangan analitik (Fujitsu), pipet mikro (Accumax), spektrofotometer UV-VIS (thermo scientific). Bahan yang ini adalah aquabidest, etanol pro analis (Sigma Lab), metanol (Merck), HCl (Sigma Aldrich), Folin-Ciocalteu (Merck), Na2CO3 (Merck) dan 1,1-difenil-2-pikrilhidazil (DPPH) (Merck), NaCl, FeCl3 (Merck), AlCl3 (Merck), quercetin (Sigma Aldrich), kalium asetat, asam tanat (Merck), asam galat (Sigma Aldrich). Sampel yang digunakan adalah buah alpukat diperoleh di Lubuk Linggau Sumatera Selatan. Identifikasi tanaman dilakukan di Herbarium ANDA Jurusan Biologi FMIPA Universitas Andalas.

\subsection{Preparasi dan ekstraksi sampel}

Kulit alpukat di iris tipis dan dikering anginkan selama 5 hari. Selanjutnya kulit alpukat diblender kasar. Serbuk kasar kulit alpukat 600 g diekstraksi dengan metode maserasi menggunakan etanol pro analis 70\% selama 9 hari. Maserat yang diperoleh diuapkan untuk mendapatkan ekstrak kental, lalu dihitung rendemen.

$\%$ Rendemen $=\frac{\text { Berat hasil ekstrak }(g)}{\text { Berat sampel awal }(g)} \times 100 \%$

\subsection{Skrining flavonoid dan tanin}

Ekstrak etanol kulit masing-masing 50 mg dilarutkan dengan $5 \mathrm{~mL}$ metanol (Merck) lalu dipanaskan. Selanjutnya, ditambahkan serbuk Mg dan 2-3 tetes $\mathrm{HCl}$ pekat. Hasil positif terbentuknya warna merah muda atau jingga. Ekstrak etanol kulit dan biji alpukat $50 \mathrm{mg}$ 
dilarutkan dengan $5 \mathrm{~mL}$ etanol (Sigma Lab). Lalu, ditambahkan 2-3 tetes $\mathrm{FeCl}_{3}$. Reaksi positif bila terbentuknya warna biru atau hijau kehitaman (Marjoni, 2016).

\subsection{Uji aktivitas antioksidan}

\subsubsection{Pembuatan larutan DPPH 0,1 mM}

DPPH sebanyak 3,94 mg dilarutkan dengan metanol hingga $100 \mathrm{~mL}$ di dalam labu ukur $100 \mathrm{~mL}$. Larutan dihomogenkan hingga diperoleh larutan DPPH 0,1 M.

\subsubsection{Pembuatan larutan pembanding asam galat}

Asam galat $10 \mathrm{mg}$ ditambahkan metanol $10 \mathrm{~mL}$ kedalam labu ukur sehingga konsentrasi $1000 \mu \mathrm{g} / \mathrm{mL}$ lalu dihomogenkan. Larutan induk dipipet 0,25 mL diencerkan dengan metanol hingga volume $25 \mathrm{~mL}$ sehingga menjadi $10 \mu \mathrm{g} / \mathrm{mL}$ lalu dibuat konsentrasi 1, 2, 3, 4, dan $5 \mu \mathrm{g} / \mathrm{mL}$. 2.4.3 Penetapan aktivitas antioksidan

Ekstrak etanol kulit alpukat dengan konsentrasi 100, 80, 60, 40 dan 20 mg/mL dan larutan DPPH masing-masing diambil dengan perbandingan 2:1 dinkubasi selama 30 menit ditempat yang gelap. Selanjutnya, diukur nilai absorbansi dengan spektrofotometri UV-Vis pada panjang gelombang $515 \mathrm{~nm}$. Kemudian dihitung persen inhibisi dan nilai $\mathrm{IC}_{50}$.

\subsection{Kadar total flavonoid dan total tanin}

\subsubsection{Pembuatan larutan sampel uji}

Ekstrak etanol kulit alpukat $25 \mathrm{mg}$ dan dilarutkan dalam $25 \mathrm{~mL}$ etanol p.a.

\subsubsection{Pembuatan kurva baku quercetin dengan pereaksi $\mathrm{AlCl}_{3}$}

Larutan kuersetin $1 \mathrm{~mL}$ dengan konsentrasi $6,8,10,12,14 \mu \mathrm{g} / \mathrm{mL}$ masing-masing dimasukkan ke dalam gelas kimia, kemudian ditambahkan $1 \mathrm{~mL} \mathrm{AlCl} 3$ 10\%, $1 \mathrm{~mL}$ kalium asetat 1 mol/L lalu dihomogenkan dan diinkubasi selama 30 menit. Serapan larutan diukur dengan spektrofotometer UV-VIS pada panjang gelombang $427 \mathrm{~nm}$. Selanjutnya, dibuat kurva kalibrasi hubungan konsentrasi kuersetin $\mu \mathrm{g} / \mathrm{mL}$ dan absorbansi sehingga diperoleh persamaan regresi linear.

\subsubsection{Penetapan total flavonoid}

Ekstrak etanol kulit alpukat $1 \mathrm{~mL}$ dimasukan ke dalam gelas kimia, kemudian ditambahkan $1 \mathrm{~mL} \mathrm{AlCl}_{3}$ 10\%, $1 \mathrm{~mL}$ kalium asetat $1 \mathrm{~mol} / \mathrm{L}$ lalu dihomogenkan, dan diinkubasi selama satu jam. Serapan larutan diukur dengan spektrofotometer UV-VIS pada panjang gelombang $427 \mathrm{~nm}$. Kadar total flavonoid yang diperoleh dinyatakan dengan mg ekuivalen kuersetin/g ekstrak.

\subsubsection{Pembuatan kurva baku asam tanat dengan reagen folin-ciocalteu}

Larutan standar asam tanat $1 \mathrm{~mL}$ dengan konsentrasi 5, 10, 30, dan $40 \mu \mathrm{g} / \mathrm{mL}$ masingmasing dimasukkan ke dalam gelas kimia ditambahkan $1 \mathrm{~mL}$ reagen Folin-Ciocalteu dibiarkan selama tiga menit, kemudian ditambahkan $1 \mathrm{ml} \mathrm{Na}_{2} \mathrm{CO}_{3} 20 \%$ jenuh lalu dihomogenkan. Setelah 
172 | Isromarina, dkk /Jurnal Ilmiah Farmasi (Scientific Journal of Pharmacy) Special Edition 2022, 169174

itu, diinkubasi selama 40 menit. Serapan larutan diukur dengan spektrofotometer UV-VIS pada panjang gelombang 655,5 nm. Selanjutnya, dibuat kurva kalibrasi hubungan konsentrasi FolinCiocalteu $\mu \mathrm{g} / \mathrm{mL}$ dan absorbansi sehingga diperoleh persamaan regresi linear.

\subsubsection{Penetapan total tanin}

Ekstrak etanol kulit alpukat $1 \mathrm{~mL}$ dimasukkan ke dalam gelas kimia ditambahkan $1 \mathrm{~mL}$ reagen Folin-Ciocalteu dibiarkan selama tiga menit, kemudian ditambahkan $1 \mathrm{ml} \mathrm{Na}_{2} \mathrm{CO}_{3} 20 \%$ jenuh lalu dihomogenkan. Setelah itu, diinkubasi selama 40 menit. Serapan larutan diukur dengan spektrofotometer UV-VIS pada panjang gelombang 655,5 $\mathrm{nm}$. Kadar total tanin yang diperoleh dinyatakan dengan mg ekuivalen asam tanat/g ekstrak.

\section{Hasil dan Pembahasan}

Hasil ekstraksi 600 g serbuk kasar kulit Persea americana Mill. dengan etanol 70\% diperoleh ekstrak kental dengan jumlah seperti pada Tabel 1.

Tabel 1. Hasil ekstraksi dan persen rendemen ekstrak etanol kulit alpukat

Berat ekstrak (g) $\quad$ Rendemen (\%)

46,54

15,51

Berdasarkan skrining fitokimia ekstrak etanol kulit alpukat mengandung flavonoid dan tanin (Tabel 2). Berdasarkan penelitian Vinha dkk (2013), kulit alpukat mengandung fenol, flavonoid dan karatenoid. Menurut Aminah dkk (2017) kulit alpukat yang dimaserasi dengan pelarut etanol 96\% mengandung flavonoid. Menurut Pramono (1986) tanin merupakan senyawa fenol dalam bentuk polimer dengan struktur kompleks.

Tabel 2. Skrining flavonoid dan tanin

\begin{tabular}{lll}
\hline Uji Fitokimia & Hasil & Keterangan \\
\hline Flavonoid & Warna merah bata & + \\
Tannin & Warna hijau & + \\
\hline
\end{tabular}

Uji aktivitas antioksidan ekstrak etanol kulit alpukat menggunakan DPPH sebagai radikal bebas. Berdasarkan penelitian, ketika ekstrak ditambah dengan DPPH terjadi perubahan warna ungu ke kuning. Hal ini menunjukkan bahwa terjadi reaksi antara ekstrak etanol kulit alpukat dan DPPH. Menurut Molyneux (2004) senyawa yang berperan sebagai antioksidan akan menangkap radikal sehingga akan mereduksi DPPH membentuk DPPH-H yang tereduksi. Hal ini ditunjukkan dengan adanya perubahan warna DPPH ungu menjadi kuning. Elektron yang tidak berpasangan pada DPPH telah berpasangan dengan hidrogen pada senyawa antioksidan.

Persen inhibisi aktivitas ekstrak etanol kulit alpukat pada konsentrasi yang berbeda menyebabkan perbedaan kekuatan inhibisi (Tabel 3). Perbedaan tersebut menunjukkan bahwa semakin tinggi konsentrasi ekstrak akan menaikkan persen inhibisi. Menurut Duh (1997) peredaman radikal bebas DPPH meningkat dengan peningkatan konsentrasi ekstrak, namun akan menurun dengan penambahan konsentrasi yang lebih besar lagi (Lai dkk, 2001). 
173 | Isromarina, dkk /Jurnal Ilmiah Farmasi (Scientific Journal of Pharmacy) Special Edition 2022, 169174

Berdasarkan persen inhibisi tersebut ekstrak etanol kulit alpukat memiliki aktivitas antioksidan dengan nilai $\mathrm{IC}_{50} 41,93 \mu \mathrm{g} / \mathrm{mL}$ dengan kategori kuat (Tabel 3), Menurut Molyneux (2004) nilai $\mathrm{IC}_{50}<50 \mu \mathrm{g} / \mathrm{mL}$ sangat kuat, $50-100 \mu \mathrm{g} / \mathrm{mL}$ kuat, $100-150 \mu \mathrm{g} / \mathrm{mL}$ sedang, $150-200 \mu \mathrm{g} / \mathrm{mL}$ lemah.

Tabel 3. Persen inhibisi dan nilai ic50 aktivitas antioksidan ekstrak etanol kulit alpukat

\begin{tabular}{clll}
\hline Sampel & Konsentrasi $(\boldsymbol{\mu g} / \mathbf{m L})$ & \% Inhibisi & $\mathbf{I C}_{\mathbf{5 0}}(\boldsymbol{\mu g} \mathbf{g} \mathbf{m L})$ \\
\hline \multirow{3}{*}{ Ekstrak Etanol Kulit } & 20 & 39,25 & \\
Alpukat & 40 & 46,71 & \\
& 60 & 60,89 & 41,93 \\
& 80 & 70,44 & \\
Asam Galat & 100 & 82,38 & \\
& 1 & 17,79 & \\
& 2 & 26,12 & \\
& 4 & 34,90 & 4,492 \\
& 5 & 46,62 & \\
\hline
\end{tabular}

Pada penetapan kadar flavonoid menggunakan quersetin dan kadar tanin menggunakan asam tanat, perhitungan menggunakan persamaan regresi linear pada kurva kalibrasi yang diperoleh dari hubungan antara konsentrasi kuersetin dan asam tanat dengan absorbansi (Gambar 1 dan 2).

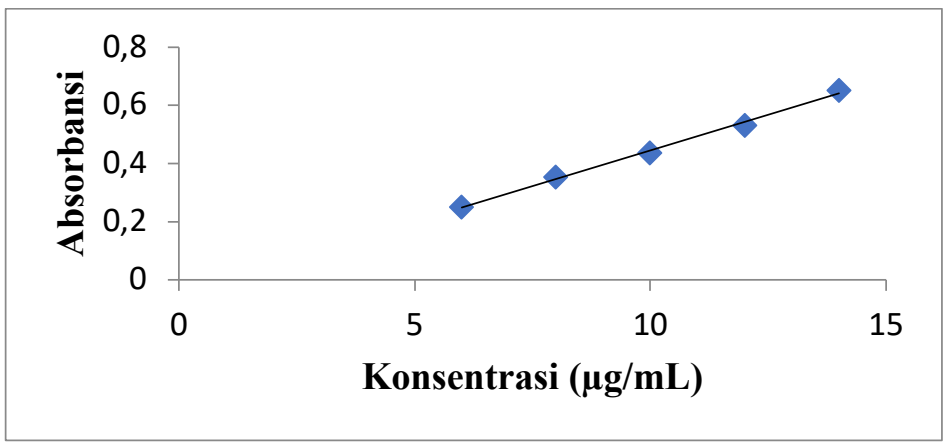

Gambar 1. Kurva kalibrasi kuercetin

Ekstrak etanol kulit alpukat mengandung total flavonoid 125,01 mg QE/g ekstrak dan total tanin 53,82 mgTAE/g ekstrak (Tabel 4). Hal ini menunjukkan bahwa kadar flavonoid pada ekstrak etanol kulit aplukat lebih tinggi dibandingkan dengan kadar tanin. Menurut penelitian Aminah dkk (2017) ekstrak etanol kulit alpukat mengandung total flavonoid 4,01 mgQE/g ekstrak. Berdasarkan penelitian Vinha dkk (2013) ekstrak kulit alpukat memiliki kadar flavonoid $44,3 \mathrm{mg} / 100 \mathrm{~g}$ ekstrak.

Tabel 4. Kadar total flavonoid dan tanin ekstrak etanol kulit alpukat

\begin{tabular}{ll}
\hline Kadar total flavonoid & Kadar total tanin \\
\hline $125,01 \mathrm{mgQE} / \mathrm{g}$ ekstrak & 53,82 mgTAE/g ekstrak \\
\hline
\end{tabular}




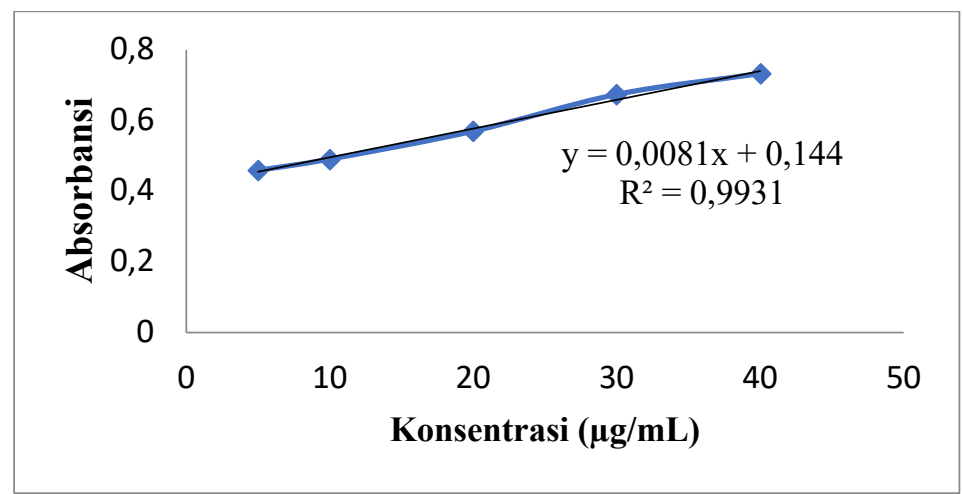

Gambar 2. Kurva kalibrasi asam tanat

Hal ini menunjukkan bahwa ekstrak etanol kulit P. americana Mill. mengandung flavonoid dan tanin yang memiliki aktivitas antioksidan. Flavonoid lebih kuat berperan sebagai antioksidan dibandingkan dengan tanin pada ekstrak etanol kulit alpukat karena jumlahnya yang lebih banyak. Gugus karboksil pada fenol berperan sebagai pendonor atom hidrogen kepada senyawa radikal bebas sehingga bersifat sebagai antioksidan dan dapat menstabilkan oksigen reaktif. Flavonoid dan tanin merupakan golongan senyawa fenol yang memiliki gugus hidroksil yang mampu meredam radikal bebas.

\section{Kesimpulan}

Ekstrak etanol kulit alpukat memiliki aktivitas antioksidan dengan nilai IC $\mathrm{I}_{50} 41,93 \mu \mathrm{g} / \mathrm{mL}$, mengandung total flavonoid 125,01 mg QE/g ekstrak dan total tanin 53,82 mgTAE/g.

\section{Daftar Pustaka}

Aminah et al., (2017), Penetapan Kadar Flavonoid Total Ekstrak Etanol Kulit Buah Alpukat (Persea americana Mill.) Dengan Metode Spektrofotometri Uv-Vis, Jurnal Fitofarmaka Indonesia, 4(2). 226-229

Duh, P.D., et al., (1997), Antioxidant Activity of Mung Bean Hulls, J. Am. Oil Chem. Soc, 74. 10591063

Lai, L.S et al., (2001), Studies on the antioxidative Actibities of Hsian-tsao (Mesona Procumbens Hemsl) Leaf Gum, J. Agric. Food Chem, (49). 963-968

Liochev, S. I. (2013), Reactive oxygen species and the free radical theory of aging, Free Radic Biol Med, (60). 1- 4

Malangngi, L.P et al., (2012), Penentuan Kandungan Tanin dan Uji Aktivitas Antioksidan Ekstrak Biji Buah Alpukat (Persea americana Mill.), Jurnal Mipa Unsrat, 1(1). 5-10

Marjoni, M.R. (2016). Dasar-dasar fitokimia diplomat III farmasi. Jakarta: CV.Trans Info Media

Molyneux, P. (2004), The Use of The Stable Free Radical Diphenylpicrylhydrazyl (DPPH) For Estimating Antioxidant Activity, Journals science and technology, 26(2). 211-219

Pramono, S. (1986). Tinjauan Umum Senyawa - Senyawa Fenol Nabati.: Yogyakarta : UGM

Vinha, A.F et al., (2013), Physicochemical parameters, phytochemical composition and antioxidantactivity of the algarvian avocado (Persea americana Mill.), Journal of Agricultural Science, 5(12). 100-109

Winarsih, H. (2007). Antioksidan Alami dan Radikal Bebas. Yogjakarta: Kanisius 